\title{
A Plateholder for Precise Roentgenography in Connection with Fluoroscopy
}

\author{
by
}

\section{Gösta Forssell}

At the X-ray examination of the gastro-intestinal tract, and especially at the examination of the duodenum, it is often important to fix on the plate a picture which appears at a certain moment on the screen. For this purpose some fluoroscopic supports are so arranged that the screen

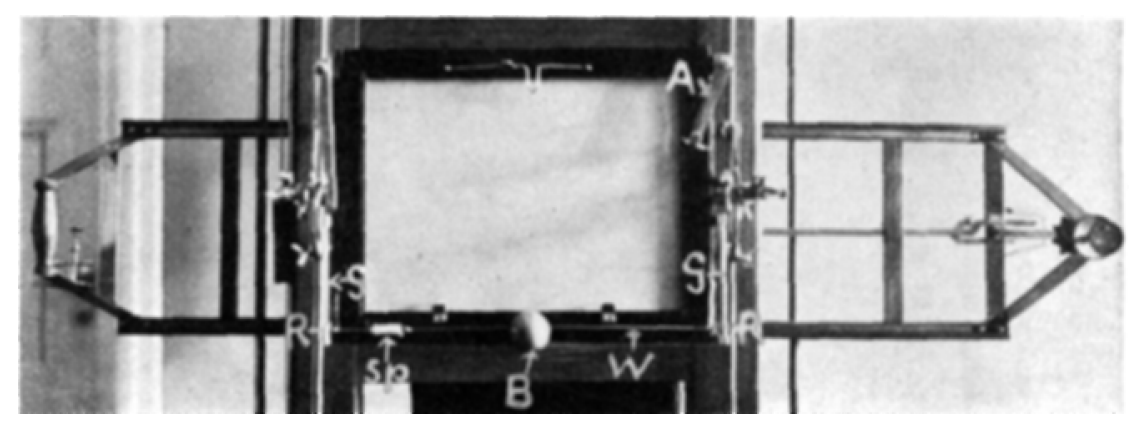

Fig. 1 .

is placed in an iron frame, from which it may be removed in order to be exchanged for a photographic plate. I myself have also made such an arrangement on my apparatus for vertical fluoroscopy. (Fig. 1.)

I formerly used plates of the size of the screen when making photographs in connection with fluoroscopy, whereby the cassette was fixed by the same spring-arm (A) as the screen. However, with this arrangement it was neither possible to make an accurate adjustment of a small plate to the sharply limited small area of the screen nor to keep it fixed there.

Since 1917 I have overcome these difficulties by a simple construction, which I demonstrated at the meeting of the Nordisk Forrening for 
Medicinsk Radiologi * in Christiania in July, 1919, and at a lecture at the Mayo Clinic, Rochester, Minn. in July, 1920.

On both the left and the right side of the iron frame which surrounds the screen fine vertical guides (G) are placed (Fig. 1.) which reach half way up the height of the screen, and attached to each of these guides is a sliding ring ( $R$ ) which can be moved up and down the guide. These two rings are connected with each other by means of a thin, horizontal steel wire (W), which is kept tense by a spring. (Sp.). On this wire a wooden ball (B) is suspended which is movable laterally. This ball serves to indicate the centre of a limited picture on the screen

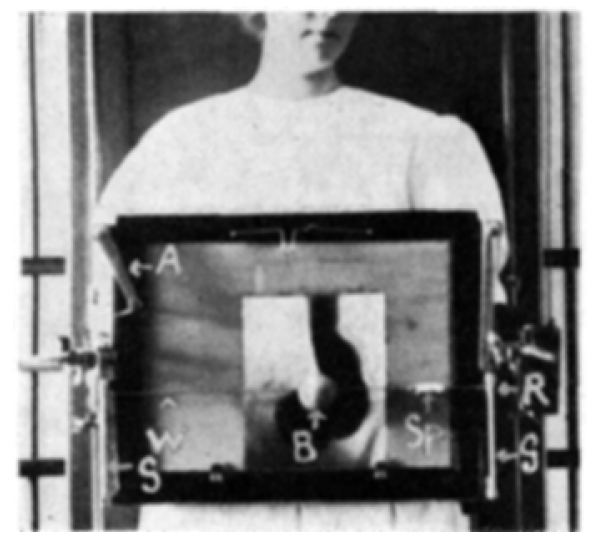

Fig. 2.

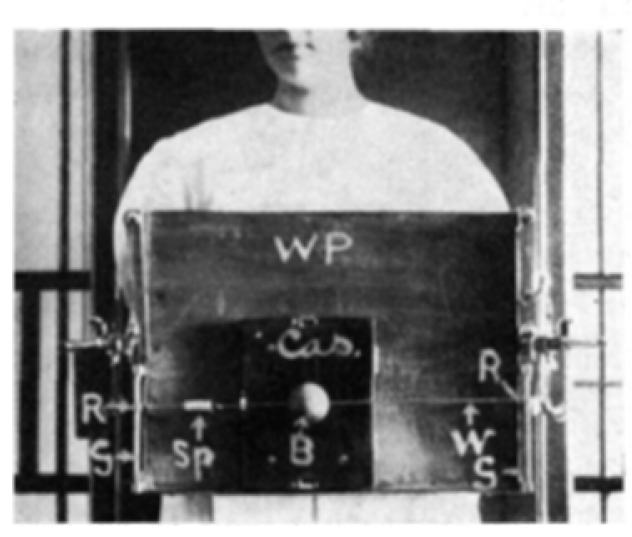

Fig. 3 .

as well as to fix a cassette exactly to this place. When the indicatorfixator is not used, the ball is lowered to the lower border of the screen (Fig. 1) in order to prevent the ball from being seen on the fluorescent surface.

When observing a detail during fluoroscopy that I wish to roentgenograph, I limit the interesting area of the picture on the lower part of the screen and place the ball just in front of it. (Fig. 2.) The screen is then quickly removed and a cassette of convenient size is placed behind the ball, the ball indicating the very centre of the limited picture. The ball keeps the cassette steadily pressed against a thin wooden plate (Fig. 3) framed by the iron screenholder. In this way I am able in a few seconds to accurately adjust a plate of convenient size onto the sharply limited area of the screen; a supply of cassettes always being ready to hand in a leaden box close to the fluoroscopic apparatus.

The X-ray tube is surrounded by an adequate layer of lead and leadrubber, and the screen is covered with leadglass, protecting effectively against the rays used at 4 - Acta Radiologica. Vol. I. 1921 
the fluoroscopy. At the radiography the examinator retires behind a leaden wall. The above-mentioned X-ray examination can, in this way, be made without danger to the radiologist.

This ball-indicator on the screen has been very useful for the development of our technic for X-ray examination of the stomach and duodenum. Through an immediate exposure of an image limited at the fluoroscopy I am enabled to obtain the best possible roentgenogram at the very moment when the picture offers the most appropriate opportunity of observing the alteration that I wish to study.

This technic demands less and smaller plates than the method of using big series of plates in order to find the most instructive pictures. I also think that the combination of roentgenography and fluoroscopy, performed in this way, is the most appropriate method of making an $\mathrm{X}$-ray examination of the stomach and the duodenum.

\section{Summary}

The article describes a new construction for centering and fixation of small plates on' the place of a limited picture on the screen by vertical fluoroscopy.

The fluoroscopic screen is supported by an iron holder, framing a thin wooden plate. Guides are placed both on the right and the left side of the holder, and these are connected with each other by a thin, horizontal steel wire, kept tense by a spring and movable vertically on the guides. A wooden ball is movable on the wire laterally. When a picture is limited for roentgenography by the fluoroscopy, the ball is placed just in front of it, the screen is removed and a cassette of convenient size is put behind the ball, which presses the cassette against the wooden plate framed by the screenholder. By this arrangement it is possible to take sharply limited pictures on small plates very speedily during the vertical fluoroscopy. 